\title{
TERAPI PIJAT IBU HAMIL UNTUK MENGURANGI SPASME OTOT PADA MASA TRIMESTER AKHIR KEHAMILAN
}

\author{
Ni Luh Kade Suarniti ${ }^{1}$,Putu Lakustini Cahyaningrum ${ }^{2}$, Ida Bagus Wiryanatha ${ }^{3}$ \\ 1,2,3 Program Studi Kesehatan Ayurweda Fakultas Kesehatan UNHI \\ Email:Kadesuarnity@gmail.com
}

\begin{abstract}
Abstrak
Menjaga keseimbangan tubuh selama masa kehamilan sangat penting dari awal sampai akhir kehamilan, agar tidak terjadi gangguan yang tidak diinginkan salah satunya spasme otot. Gangguan spasme otot yang menimbulkan rasa nyeri dapat mengganggu ibu hamil dalam beraktifitas. Salah satu cara untuk mengurangi spasme otot adalah dengan terapi pijat. Tujuan dari penelitian ini untuk mengetahui dan memahami terapi pijat ibu hamil dapat mengurangi spasme otot, mengetahui tata cara yang digunakan dalam terapi pijat ibu hamil untuk mengurangi spasme otot, dan implikasi terapi pijat ibu hamil. Penelitian ini menggunakan metode snow ball sampling, jenis penelitian kualitatif. Menggunakan teori fungsionalisme struktural serta pendekatan ayurweda khususnya snehana. Penelitian ini dilakukan di Kota Denpasar pada tempat terapi pijat ibu hamil dengan objek penelitian praktisi pijat dan ibu hamil trimester akhir. Data dalam penelitian ini diperoleh melalui observasi, wawancara dan dokumentasi. Berdasarkan hasil penelitian, terapi pijat dapat mengurangi spasme otot karena pijat dapat mengurangi tekanan dari saraf dan otot, melancarkan peredaran darah keseluruh tubuh, dan dapat meningkatkan daya tahan tubuh ibu hamil. Tata cara pijat yang digunakan sama dengan pijat pada umumnya tetapi berbeda dalam teknik pengambilan dengan tiga teknik yaitu mengusap, memutar, dan meremas (effleurage, friksi, dan petrisage), dengan melakukan pemijatan secara rutin didapatkan Implikasi yaitu: Mengurangi rasa nyeri punggung ibu hamil, meningkatkan kualitas tidur, dan menimbulkan perasaan bahagia pada ibu hamil.

Kata Kunci : "Pijat, ibu hamil, Spasme Otot"
\end{abstract}

\section{ABSTRACT}

Maintaining body balance during pregnancy is very important from the beginning to the end of pregnancy, so that no unnecessary problems occur one of the muscle spasms. Muscle disorders that cause pain can cause pregnant women to indulge. One way to reduce muscle spasms is with massage therapy. The aim of this research is to study and evaluate maternal massage therapy to reduce muscle spasms, understand the procedures used in massage therapy for pregnant women to reduce muscle spasms, and the implications of massage therapy for pregnant women. This research uses snow ball sampling method, qualitative research type. Uses structural functionalism theory and seeks snehana special ayurweda. This research was conducted in Denpasar City at the place of massage therapy for pregnant women with the object of conservation research and late trimester pregnant women. Data in this study were obtained through observation, interviews and documentation. Based on research results, massage therapy can reduce muscle mass because it can reduce pressure on muscles, improve blood circulation throughout the body, and can increase endurance of pregnant women. The massage procedures used are the same as the massage methods in general but differ in the technique of straightening, rotating, and squeezing (effleurage, friction, and petrisage), by using massage routinely can be found Implications namely: Reducing the comfort of a pregnant woman's back, improving sleep quality, and increase feelings of happiness in pregnant women.

Keywords: "Massage, Pregnant Women, Muscle Spasm" 


\section{Pendahuluan}

Kehamilan didefinisikan sebagai fertilisasi atau penyatuan sukra (benih laki-laki/sperma) dengan sonita (sel telur wanita) yang menghasilkan pembuahan, embrio, fetus atau bhruna di dalam kandungan (garbhasaya/ uterus) seorang ibu atau calon ibu (Nala, 2001:119). Proses kehamilan menurut Fauziah dan Sutejo (2012:4) terjadi kira-kira selama sepuluh bulan lunar atau sembilan bulan kalender (40 minggu/280 hari). Proses kehamilan dibagi menjadi 3 (tiga) trimester, dimana trimester I berlangsung selama 12 minggu, trimester II dari minggu ke-13 hingga ke-28, dan trimester III dari minggu ke-29 hingga ke-40. Pada trimester akhir perubahan-perubahan yang terjadi pada ibu menimbulkan rasa yang tidak nyaman, sehingga mengganggu aktivitas ibu hamil seperti istirahat atau pola tidur, terjadinya peningkatan urinasi, konstipasi/sulit buang air besar, kesulitan dalam bergerak dan salah satu keluhan yang sering dialami pada ibu hamil adalah spasme otot (Fauziah dan Sutejo, 2012:85). Spasme otot yang terjadi pada ibu hamil memiliki gejala seperti nyeri punggung, terasa kaku dan kram pada otot punggung yang terjadi secara tiba-tiba. Selain spasme otot pada punggung, spasme juga dapat terjadi pada otot lainnya seperti otot paha dan betis.

Dewasa ini upaya penanggulangan untuk mengurangi spasme otot yang dialami oleh ibu hamil dapat menggunakan dua cara yaitu dengan terapi farmakologi dan non farmakologi (Kartikasari dan Nuryanti, 2016:299). Terapi non farmakologi adalah terapi yang tanpa menggunakan obat-obatan kimia atau yang disebut dengan pengobatan komplementer. Pengobatan komplementer merupakan pelengkap pengobatan kedokteran modern (Hidayati dan Mangoenprasadjo, 2005:4) seperti yoga, akupuntur, terapi herbal, terapi sinar, meditasi, relaksasi dan yang paling popular di masyarakat sampai saat ini adalah terapi pijat. Terapi pijat ibu hamil atau massage ibu hamil merupakan suatu teknik dengan sentuhan pada bagian tubuh tertentu yang bertujuan untuk meringankan rasa tidak nyaman selama masa kehamilan berlangsung (Diana, 2017:154). Menurut Becker (2007:116-117) terapi pijat ibu hamil ialah suatu sentuhan yang lembut pada tubuh ibu hamil dengan menggunakan lebih banyak teknik effleurage atau mengusap, selain itu gerakan terapi pijat yang diterapkan pada ibu hamil sedikit berbeda dari terapi pijat biasa, dimana terapi pijat yang dilakukan penuh dengan pertimbangan, seperti memperhitungkan tekanan serta gerakan yang diberikan karena ada beberapa titik pijat yang boleh dan tidak boleh diambil pada ibu hamil agar tidak mengganggu perkembangan janin.

Terapi pijat juga dikenal dapat mengatasi berbagai keluhan yang terjadi pada sistem tubuh seperti dapat memperbaiki sistem saraf, meningkatkan fleksibelitas otot, memperlancar tekanan darah, melancarkan buang air besar, dapat memperbaiki kinerja paruparu, dan dapat membantu dalam masalah sulit tidur atau insomnia.

\section{Metode Penelitian}

Penelitian ini menggunakan data kualitatif. Data kualitatif yang diperoleh melalui berbagai macam teknik pengumpulan data yaitu dengan wawancara, mencatat kajian pustaka mengamati atau observasi. Data kualitatif adalah data yang berbentuk kata-kata, bukan dalam bentuk angka. Bentuk lain dari data kualitatif adalah gambar yang diperoleh melalui pemotretan atau rekaman video (Dharma, 2008:5).

Prosedur pengumpulan data merupakan teknik atau cara-cara yang dapat digunakan oleh peneliti untuk mengumpulkan data. Instrumen pengumpulan data merupakan alat bantu yang dipilih dan digunakan peneliti dalam kegiatan pengumpulan data agar kegiatan tersebut menjadi sistematis dan akurat. Data yang dikumpulkan dalam penelitian digunakan untuk menjawab masalah yang telah dirumuskan.

\section{Hasil Penelitian}

1. Mengurangi Ketegangan dari Saraf dan Otot

Memberikan pemijatan pada ibu hamil trimester akhir dapat membantu mengurangi tekanan pada saraf dan otot, hal ini dikarenakan gerakan pijat mampu menstimulasi saraf dan otot-otot yang tegang sehingga menjadi relaks. Jaringan saraf dan otot yang mengalami relaksasi dapat merangsang tubuh secara otomatis untuk meningkatkan hormon endorphine yang dihasilkan secara alami oleh otak, hormon endorphine berfungsi mengurangi rasa nyeri yang ditimbulkan dari spasme otot.

Kartikasari dan Nuryanti (2016:303) juga menjelaskan pijatan yang diberikan pada ibu hamil dapat merelaksasi saraf-saraf dan otot sehingga merangsang keluarnya hormon endorphin di dalam tubuh. Hormon endorphine merupakan salah satu hormon alami yang diproduksi oleh hipotalamus yang berada pada otak tengah, hormon endorphine berfungsi sebagai pengontrol rasa nyeri dan ketegangan pada seseorang sehingga dengan meningkatnya aliran hormon endorphine pada ibu hamil dapat membuat ibu merasa nyaman, releks dan mengurangi rasa nyeri yang timbul saat 
mengalami spasme otot.

Pernyataan di atas sesuai dengan maanfaat yang didapatkan dari terapi snehana dalam ayurweda yaitu membaluri tubuh dengan minyak sehingga minyak dapat meresap ke dalam kulit dan membuat kulit dan otot menjadi relaks dan dapat melancarkan aliran darah (Nala, 2001:79). Lebih lanjut Dash dan Ramaswamy (2006:95) menyatakan bahwa menurut ayurweda dengan melakukan pemijatan pada bagian tubuh tertentu dapat membantu mengatasi kelelahan, mengurangi tekanan yang terjadi pada saraf dan otot, menyegarkan badan dan mengurangi ketegangan.

\section{Melancarkan Peredaran Darah}

Berdasarkan wawancara dengan 13

(tigabelas) ibu hamil yang mengalami spasme otot dan 10 (sepuluh) orang praktisi pijat yang diwawancarai, semua menyatakan bahwa terapi pijat yang dilakukan pada ibu hamil dapat melancarkan dan menyeimbangkan peredanan darah ke seluruh tubuh sehingga dapat mengurangi rasa nyeri yang terjadi pada otot-otot punggung ibu hamil. Hal ini terjadi karena pijat berupa sentuhan pada ibu hamil juga dapat mengurangi tekanan pada arteri dan vena yang membuat peredaran darah mengalir tanpa hambatan ke seluruh tubuh. Aliran oksigen yang mengalir menjadi lancar, darah yang mengalir tidak hanya membawa oksigen tetapi darah juga membawa berbagai komponen penting untuk tubuh seperti nutrisi, hormon, dan lainlainnya.

Pendapat di atas didukung oleh Wijayanti (2009:291) menjelaskan pijat ibu hamil merupakan perawatan terapeutik berupa sentuhan yang diberikan pada kulit dan otot bertujuan untuk merangsang sirkulasi di dalam tubuh dan menyeimbangkan aliran darah ke seluruh tubuh. Tubuh akan merespon untuk meningkatkan sirkulasi darah dengan memproduksi sel darah merah yang membawa oksigen dan nutrisi yang terkandung dalam darah ke seluruh tubuh sehingga dapat mengurangi rasa nyeri yang timbul dan mencegah terjadinya kelelahan saat masa kehamilan.

\section{Meningkatkan Daya Tahan Tubuh Ibu Hamil}

Pijat yang diberikan pada ibu hamil mampu merelaksasi otot yang berkontraksi, menstimulasi saraf yang berhubungan dengan organ-organ dan kelenjar yang ada di dalam tubuh sehingga dapat melancarkan aliran energi ke seluruh. Energi yang mengalir ke seluruh tubuh membuat daya tahan tubuh meningkat, agar ibu hamil terhindar dari keluhan-keluhan yang terjadi saat mengalami spasme otot. Hal ini didukung oleh
Kartikasari dan Nuryanti (2016:301) menyatakan pijat yang diberikan pada punggung ibu hamil dapat membantu mengurangi rasa nyeri punggung dan membantu merangsang hormon endorphine sehingga dapat meningkatkan relaksasi, secara sistematis ibu hamil yang merasa relaks kesehatan tubuhnya akan menjadi meningkat.

Pendapat di atas didukung oleh Lad dan Svoboda (2007:175) menjelaskan bahwa pijat adalah salah satu pengobatan yang dapat menghilangkan kekakuan atau ketegangan, mengeluarkan zat yang tidak berguna bagi tubuh, mengendalikan unsur tri dosha di dalam tubuh dengan mengikuti aliran tenaga di dalam tubuh sehingga menjadi seimbang, dengan seimbangnya unsur tri dosha di dalam tubuh secara langsung membuat daya tahan tubuh akan meningkat. Lebih lanjut Wijayanti (2009:224) menjelaskan pijat yang diberikan secara rutin dengan minyak dan dengan aroma yang sesuai dapat mengurangi rasa tidak nyaman yang dialami ibu selama masa kehamilan berlangsung serta dapat meningkatkan sistem kekebalan tubuh ibu hamil.

Menurut Kaushal, Lohith, dan Ashvini (2017:245) menjelaskan dalam ayurweda ada berbagai jenis pijat sesuai dengan kebutuhan dan metode, Snehana merupakan salah satu dari pancha karma yang diberikan untuk penyembuhan. Snehana berasal dari kata "Snih" yang berarti perekat atau dilekatkan, jadi senehana diartikan sebagai terapi dengan cara melekatkan bahan obat pada tubuh yang berupa minyak bertujuan untuk suatu penyakit dan menyeimbangkan unsur tri dosha di dalam tubuh. Snehana disebut juga dengan abhyangga atau sneha-vidhi. Abhyangga berarti teknik pijat yang menggunakan minyak. Hal ini termasuk dalam Sneha-Vidhi yang berarti terapi dengan menggunakan minyak yang memiliki khasiat obat tertentu untuk menyeimbangkan unsur tri dosha.

Pernyataan di atas didukung oleh Lochan (2017 : 213) bahwa dalam Astangga Hridaya, Acharya Vagbhata menjelaskan SnehaVidhi adalah suatu teknik pengobatan menggunakan minyak obat yang disesuaikan dengan keadaan pasien. Dalam penggunaan bahan minyak dan banyaknya minyak yang digunakan tergantung pada penyebab dari keluhan yang terjadi pada pasien. Spasme otot yang terjadi pada ibu hamil karena disebabkan oleh meningkatnya vata pada bagian tubuh sehingga menyebabkan kontraksi otot berlebih yang menimbulkan rasa nyeri.

Lebih lanjut Joseph, Cherian, dan CT Joseph (2012 : 164) menjelaskan teknik abhyangga 
yang menggunakan minyak dengan jenis minyak yang tepat dapat menurunkan unsur vata sehingga menjadi seimbang, penggunaan minyak yang tepat pada ibu hamil membuat ketegangan otot yang terjadi menjadi berkurang dikarenakan unsur kapha dalam taila (minyak) tersebut berfungsi untuk menyeimbangkan unsur vata pada tubuh.

\section{Tata Cara Terapi Pijat Ibu Hamil untuk} Mengurangi Spasme Otot

\section{Menyiapkan Alat dan Bahan yang Digunakan oleh Praktisi}

Selama proses pemijatan memerlukan alat dan bahan yang digunakan untuk mempermudah praktisi dalam proses pemijatan berlangsung. Alat dan bahan yang akan digunakan sebaiknya disiapkan sebelum pemijatan dilakukan. Alat yang digunakan adalah bantal, bantal guling kecil, satu handuk kecil basah, satu handuk kecil kering, dan satu selimut yang akan digunakan oleh ibu hamil. Bahan yang digunakan yaitu minyak dan krem.

\section{Tahap Pemijatan}

\section{a. Persiapan pasien}

Melakukan wawancara merupakan salah satu cara praktisi untuk mengambil keputusan dalam mengetahui keluhan-keluhan yang terjadi pada pasien serta menjadi cara untuk menentukan gerakan pijat yang akan diberikan, setelah mengetahui keluhan-keluhan pada pasien ada beberapa persiapan yang harus dilakukan setelah wawancara yaitu mengarahkan ibu untuk melepaskan pakaian dan memposisikan diri tidur terlentang di bed dengan posisi bantal ada di atas kepala, batal guling ada di bawah lutut dan menutupi tubuh ibu dengan selimut atau kain sehingga ibu merasakan berada pada posisi yang nyaman.

Hal di atas didukung oleh Kavanagh (2008:1516) mengatakan dengan mengetahui keluhankeluhan dan keinginan dari pasien suasana kedamaian dan ketenangan akan tercipta selama proses pemijatan berlangsung, suasana yang tercipta akan membantu dalam proses kesembuhan dari pasien. Becker (2007:117-108) menambahkan memberikan posisi yang nyaman dan sesuai dengan keinginan ibu, menyangga dengan bantal guling pada posisi miring ke samping dan meletakkan guling pada bawah lutut pada posisi terlentang akan membuat ibu merasa relaks dan mengurangi lekukan pada punggung bawah.

b. Membersihkan telapak kaki dan
melakukan pelemasan
Membersihkan kaki pasien sebelum

melakukan pijat adalah salah satu cara untuk menjaga kenyamanan dan kebersihan pasien. Mengelap kaki dengan handuk basah kemudian mengeringkannya dengan handuk kering akan melemaskan kulit sekaligus membuat ibu menjadi lebih relaks. Hal ini didukung oleh Kavanagh (2008:15) mengatakan menjaga kebersihan dan membuat pasien merasa nyaman sebelum melakukan pemijatan merupakan faktor penting dalam melakukan pemijatan.

Setelah membersihkan kaki pasien dengan menggunakan handuk kemudian melakukan pelemasan pada bagian kaki dengan memutar pergelangan kaki perlahan ke kanan dan ke kiri sebanyak 3 sampai 5 kali sehingga membuat pasien merasa nyaman, selain itu membuat otot-otot di pergelangan kaki menjadi relaks. Pernyataan ini didukung oleh Becker (2007:42) menjelaskan bahwa melakukan pelemasan pada kaki sebelum memulai pemijatan dilakukan dengan mengusap kaki kemudian memutar pergelangan kaki yang bermanfaat untuk melemaskan rasa kaku pada otototot kaki dan memberi rasa nyaman.

\section{c. Pengambilan Pasien \\ - Pemijatan pada kaki}

Melakukan pemijatan pada kaki menggunakan metode usapan (effleurage) dengan tekanan yang lembut diawali dengan mengoleskan minyak dan krim ke daerah kaki berfokus untuk melemaskan otot-otot kaki dan paha. Tekanan yang diberikan melalui telapak tangan dengan membentuk huruf $\mathrm{V}$ dengan gerakan maju kedepan dengan beriringan. Ketika tangan mencapai bagian atas paha, kemudian memisahkan keduanya dan biarkan usapan pada kedua tangan berada pada sisi kaki dari atas menuju tumit tanpa tekanan. Melakukan gerakan putar (friksi) dari tumit menuju paha atas dengan menggunakan kedua ibu jari tangan. Saat di paha atas melakukan gerakan meremas (petrisage) dengan cara memegang, putar dan pijat bagian tengah, dalam dan luar.

Hal di atas didukung oleh Kuswenda, Siswanti dkk (2016:19) melakukan pemijatan pada kaki menggunakan telapak tangan ke arah atas dari pergelangan kaki sampai pangkal paha dengan teknik usapan baik untuk memberikan rasa nyaman. Becker (2007:122-123) menambahkan pemijatan pada ibu hamil dengan gerakan usapan (effleurage), putar (friksi), dan meremas (petrissage) dimana gerakan usapan (effleurage) berfungsi memberikan kesan sentuhan pertama pada kulit sebelum dan setelah pemijatan dilakukan selain itu usapan juga digunakan saat mengaplikasikan minyak pada kulit ibu hamil. Gerakan memutar (Friksi) berfungsi 
untuk menggerakkan otot secara perlahan sehingga otot mengalami relaksasi dan membuat aliran darah menjadi lancar, dan gerakan meremas (Petrissage) hanya dapat digunakan pada bagian tubuh tertentu yang memiliki daging tebal, gerakan ini memiliki fungsi untuk menyentuh otot lebih dalam dan membantu dalam meregangkan otot sehingga dapat mencegah ketegangan otot saat kelelahan. Lebih lanjut Ramesh (2006: 17) Daerah kaki dan paha merupakan tempat lemak berkumpul, permasalahan paling besar yang berhubungan dengan paha adalah selulit dan paha mengendur. Memberikan minyak dengan menggunakan gerakan petrisage atau meremas pada bagian otot paha dapat mengurai lemak yang ada di paha dan memperbaiki sirkulasi darah di paha dan kaki.

Sesuai dengan pendapat di atas Kaushal, Lohith, Asvini. (2017:247-248). Menyatakan dalam ayurweda pijat adalah salah satu terapi yang diberikan bertujuan untuk menyeimbangkan unsur tri dosha di dalam tubuh, snehana merupakan salah satu teknik pijat yang digunakan untuk menurunkan unsur vata yang berlebih di dalam tubuh. Masing-masing teknik pijat memiliki gerakan dan fungsi yang berbeda yaitu teknik meremas (petrissage) pada teknik ini pijatan dilakukan pada jaringan dengan cara digenggam dengan kedua tangan dan diangkat sehingga dapat merangsang otot-otot untuk relaksasi, pada teknik ini kontak tangan praktisi dengan tubuh pasien tidak terputus. Terakhir adalah teknik gesekan (friksi) yang diberikan dengan gerakan arah melingkar dilakukan menggunakan tekanan konstan dan alami dari jari-jari atau ibu jari.

\section{- Pemijatan pada tangan}

Pemijatan dilakukan dengan posisi miring ke kanan atau ke kiri dan disangga dengan bantal pada kepala dan diantara lutut dengan gerakan usapan (effleurage) dari pergelangan tangan hingga bahu, gerakan selajutnya dengan melemaskan sendi bahu dengan gerakan memutar (friksi) dan dilanjutkan dengan meremas (petrissage) dengan tangan berada pada lengan. Pegang dan putar otot bisep dan trisep dilengan atas secara berirama. Terakhir lemaskan jari-jari tangan dengan memutar kearah keluar dan kedalam. Hal ini didukung oleh Aprilia (2017:80) menjelaskan memberikan pijatan lembut pada tangan dari arah luar lengan mulai dari lengan sampai ke jari-jari tangan akan menenangkan sekujur tubuh ibu termasuk leher, bahu dan paha. Lebih lanjut Becker (2007:124) meyatakan pijatan pada lengan mampu menyejukkan ibu dan harus dilakukan dengan posisi miring dengan disangga oleh bantal pada bagian kepala dan lutut. Ramesh (2006:20-21) menambahkan pijatan yang diberikan pada tangan dilakukan dengan meremas pada bagian otot lengan dan melakukan effleurage dari bahu hingga ujung tangan sehingga membuat tangan dan otot-otot pada tangan menjadi relaks dan dapat melancarkan sirkulasi darah pada tangan.

\section{- Pemijatan pada perut}

Pemijatan dilakukan pada perut diharapkan membantu mengurang permasalahan pada pencernaan seperti sembelit dan diare. Gerakan yang dianjurkan dengan usapan (effleurage) kemudian memutar dari bagian luar perut ke bagian dalam, pada setiap gerakanyang diberikan pada perut dilakukan tanpa menggunakan tekanan sama sekali. Hal ini didukung oleh Becker (2007:120-121) menjelaskan bahwa pijat yang diberikan pada daerah perut ibu hamil sangat lembut dan menggunakan usapan dengan arah sesuai jarum jam dan ulangi beberapa kali dan juga ulangi yang sama pada sisi pinggang sehingga membuat bayi merasakan sentuhan yang diberikan. Pemijatan yang diberikan pada perut ibu hamil dapat membantu dalam melancarkan pencernaan, dan menyeimbangkan aliran darah pada perut sehingga melancarkan aliran nutrisi pada bayi yang ada dalam kandungan.

\section{- Pemijatan pada wajah dan kepala}

Memijat pada bagian kepala berguna untuk meredakan sakit kepala baik itu karena stress, sinus, maupun masalah pencernaan. Hal ini sangat membantu kondisi ibu hamil karena sirkulasi darah menuju wajah semakin bagus. Gerakannya effleurage pada kening tanpa tekanan, dilanjutkan pada pipi dan dagu. Memijat seluruh area kening sampai batas rambut dengan ibu jari ditengah kening dan jari-jari berada di sekitar sisi kepala. Pelemasan dagu dengan membawa gerakan ibu jari dari dalam kesisi luar wajah. Mengendurkan ketegangan kepala dengan cara memijat bagian batas tumbuh rambut dikepala dari atas kening menuju ke dasar tulang kepala dengan menggunakan gerakan friksi. Lakukan gerakan tersebut dengan lembut dan pelan.

Pernyataan di atas didukung oleh Kavanagh (2008:106-115) menjelaskan memberikan pijatan pada bagian kepala dan wajah dengan gerakan effleurage dapat menyeimbangkan energi di dalam tubuh sehingga dapat membuat ketegangan pada wajah berkurang. Lebih lanjut Ramesh (2006:29-38) menyatakan pijat dengan mengaplikasikan minyak pada kepala menggunakan gerakan menyentuh dengan lembut pada kepala dan 
wajah, kemudian sedikit memutar pada kepala sangat membantu dalam merelaksasi seseorang yang mengalami ketegangan, melancarkan peredaran darah di kepala dan wajah, memberikan nutrisi pada kulit kepala dan rambut. Becker (2007:120-121) menambahkan melakukan pijatan pada ibu hamil dilakukan dengan posisi terlentang dan dilakukan dengan lembut dengan gerakan mengusap dan memutar dengan beberapa kali sentuhan yang diulangi sehingga membuat kulit wajah ibu lembut dan lebih bersinar.

\section{- Pemijatan pada punggung}

Punggung merupakan bagian terluas dari tubuh dan bagian yang paling banyak menerima beban saat terjadi kehamilan. Terutama pada ligamen dan otot sering terjadi spasme. Pemijatan pada daerah punggung ibu hamil dengan cara posisi duduk dengan mengangkang di atas kursi atau posisi berbaring miring di atas tempat tidur. Pemijatan dimulai dari punggung bawah dengan gerakan effleurage menuju kepunggung atas, disekitar bahu dan dengan lembut menurun ke posisi awal. Letakkan ibu jari kelekukan yang ada di dasar tulang belakang dengan gerakan friksi pada bagian tulang belakang hingga leher. Letakkan satu tangan pada salah satu bahu dan letakkan ibu jari tangan lainnya diantara tulang bekang dan bidang bahu. Peras, pegang dan putar otot bahu satu persatu. Berdiri disisi ibu hamil dan lemaskan kepala bagian depan dengan meletakkan tangan diotot leher sangat perlahan dan lembut agar tidak terjadi ketegangan. Terakhir lakukan gerakan effleurage kembali seluruh punggung dengan tekanan lembut.

Dari perawatan pijat yang di berikan pada daerah punggung, ada beberapa bagian otot yang difokuskan bertujuan untuk mengurangi spasme pada otot yaitu otot trapezius (otot kerudung), muskulus latissimus dorsi (otot punggung lebar), dan muskulus rhomboid (otot belah ketupat). Pemijatan yang diberikan pada ketiga bagian otot ini dapat diberikan 5 sampai 8 kali gerakan pengulangan, sehingga durasi waktu pemijatan pada punggung dilakukan selama 10 sampai 15 menit. Wong (2012:66) menjelaskan pengambilan pijat pada ibu hamil sebaiknya dengan posisi setengah berbaring dan meletakkan bantal pada kaki sebagai penyangga, dengan posisi ini akan memberikan rasa aman pada bayi selama proses pemijatan berlangsung. Lebih lanjut Becker (2007:118-120) menjelaskan melakukan pijatan pada punggung dimulai dari punggung bawah menggerakkan tangan sampai bahu dan kembali lagi ke punggung bawah dengan gerakan effleurage lembut dan tanpa tekanan dilakukan pengulangan hingga 4 sampai 5 kali gerakan. Kemudian dilanjutkan dengan memberikan gerakan friksi pada bagian bahu turun sampai punggung atas dengan diulang 3 sampai 4 kali pengulangan. Lalu melakukan sentuhan perlahan pada bahu dan leher dengan pengulangan beberapa kali. Gerakan penutup diakhiri dengan mengusap sekali dari bahu ke leher kemudian ke bawah sampai panggul.

Lebih lanjut Aprilia (2017:80-81) menyatakan melalakukan pemijatan pada punggung dilakukan dengan membentuk huruf v ke arah luar menuju tulang rusuk, kemudian melingkar pada bagian punggung atas selanjutnya pijatan ini secara bertahap turun ke bawah hingga menyentuh seluruh bagian punggung dan diulang beberapa kali sehingga ibu merasakan relaks dan santai, selain itu ibu akan merasakan bahagia.

Ramesh (2006:15-16) menjelaskan secara ayurweda gerakan yang diberikan pada bahu dan punggung diawali dengan gerakan memutar yang diberikan pada ujung bahu secara perlahan mengarah ke luar dengan menggunakan minyak ke kedua bahu dengan bersamaan, massage punggung dengan sentuhan eflleurage pada satu sisi terlebih dahulu dari atas ke bawah hingga ke pantat gerakan saling bergantian, bagian belakang adalah bagian terbesar dan terpenting untuk dipijat, sehingga membuat punggung menjadi relaks dan sangat nyaman. Gerakan selanjutnya memberikan pijatan dengan satu tangan dibahu dan satu tangan memberikan pijatan pada punggung dengan gerakan memutar dari atas kebawah, gerakan ini bertujuan untuk merangsang aliran darah keseluruh tubuh dan memfokuskan pada otot-otot punggung.

Pijat yang diberikan pada seluruh bagian tubuh terfokus pada gerakan bertujuan untuk merelaksasi saraf dan otot. Gerakan yang diberikan sangat lembut dan tekanan yang diberikan tidak keras pada bagian tubuh ibu hamil sehingga tekanan tidak merangsang aliran vital dalam tubuh. Hal ini didukung oleh Becker (2007:118) menyatakan pijat yang dilakukan pada ibu hamil dilakukan dengan sangat hati-hati dan lembut tanpa tekanan yang bertujuan untuk merangsang terjadinya relaksasi otot yang mengalami ketegangan. Lebih lanjut Govindan (1996:28) manyatakan pijat dapat dilakukan pada seluruh aliran vital tubuh (marma) tanpa menggunakan tekanan yang berlebihan sehingga dapat meminimalisir efek yang tidak diinginkan.

Implikasi yang Ditimbulkan Setelah Melakukan Pijat Ibu Hamil 


\section{Mengurangi Rasa Nyeri Pada Punggung Ibu Hamil}

Menjaga keseimbangan tubuh ibu hamil menjadi sangat penting sehingga memerlukan tindakan untuk membuat ibu hamil selalu dalam keadaan sehat dan bahagia selama masa kehamilan. Spasme otot merupakan salah satu kondisi dimana otot mengalami kontraksi yang dapat menimbulkan rasa nyeri dan tidak nyaman saat melakukan aktivitas selama kehamilan berlangsung. Pijatan yang berupa sentuhan dan tekanan yang diberikan pada ibu hamil dapat merelaksasi otot sehingga mengurangi rasa nyeri yang dialami oleh ibu di masa kehamilan.

Hal ini didukung oleh Kartikasari dan Nuryanti (2016:302-303) menyatakan terapi pijat dapat merangsang otot-otot ibu hamil menjadi relaks sehingga tubuh dapat meningkatkan produksi hormon endorphine dan mengalirkan keseluruh bagian tubuh melalui darah, Hormon endorphine memiliki manfaat untuk memberikan rasa nyaman pada masa kehamilan hingga menjelang melahirkan, dan dapat mengurangi rasa nyeri saat sebelum melahirkan. Pijat juga merupakan sebuah terapi yang menggunakan sentuhan atau pijatan dengan tekanan ringan yang cukup diberikan kepada ibu hamil, pada waktu masa akhir dari proses kehamilan.

Pernyataan di atas juga didukung oleh Wong (2012:46) Menjelaskan terapi pijat yang diberikan kepada ibu hamil berfungsi untuk mengurangi stres, membantu memperlancar proses kehamilan dengan cara memperlancar aliran darah, limfa, mengurangi edema, membantu memaksimalkan kapasitas pernapasan yang sangat diperlukan dalam proses melahirkan.

\section{Meningkatkan kualitas tidur pada akhir kehamilan}

Terjadinya nyeri yang dialami oleh ibu hamil dapat mengganggu pola istirahat dan kualitas tidur pada ibu hamil trimester akhir, dengan terapi pijat yang diberikan pada ibu hamil trimester akhir yang mengalami spasme otot secara berkala dan rutin dapat membuat rasa nyeri yang dialami ibu hamil menjadi berkurang dan membuat ibu hamil merasa nyaman dalam bergerak atau memposisikan diri saat tidur sehingga ibu hamil dapat beristirahat dengan maksimal. Istirahat dan tidur yang berkualitas dapat membantu dalam proses mengurangi spasme otot yang terjadi selama akhir kehamilan. Hal ini didukung oleh Diana (2017) yang memaparkan tentang terapi pijat ibu hamil yang diberikan pada masa kehamilan memiliki pengaruh besar untuk kualitas tidur ibu hamil, memberi pijatan saat masa kehamilan secara berkala dapat memberikan efek relaksasi, memaksimalkan proses peregangan otot, dan meningkatkan elastisitas jaringan sehingga ibu hamil dapat bergerak dan beraktivitas dengan leluasa terutama pada saat mengambil posisi selama tidur.

Lebih lanjut Becker (2007:114-115) menjelaskan terapi pijat yang diterapkan pada ibu hamil dapat membuat ibu merasa relaks, meningkatkan perasaan optimis, rasa nyaman di masa kehamilan, membuat pola tidur ibu semakin membaik, dan mengurangi sakit punggung pada masa kehamilan. Wijayanti (2009:225) juga menyatakan pemijatan yang diberikan pada ibu hamil dapat membuat ibu hamil merasa nyaman dan kecemasan yang dialami menjadi berkurang sehingga berpengaruh pada kualitas tidur ibu hamil pada akhir kehamilan. Kuswenda, Siswanti, dkk (2016:07) menyatakan pijatan yang diberikan dapat merangsang hormon endorphine sehingga dapat merelaksasikan pikiran pada ibu hamil dan membuat tidur ibu hamil menjadi lebih nyenyak dan berkualitas.

\section{Menimbulkan Perasaan Bahagia}

Berbagai faktor dapat membuat ketidak seimbangan pada tubuh ibu hamil sehingga menimbulkan rasa kecemasan dan kegelisahan pada ibu hamil, pijat yang diberikan kepada ibu hamil dapat membuat aliran darah menjadi lancar dan merelaksasi otot-otot sehingga merangsang keluarnya hormon endorphine di dalam tubuh yang dapat mengurangi rasa nyeri yang disebabkan oleh spasme otot, perasaan bahagia juga disebabkan oleh adanya hormon endorphine di dalam tubuh. Persaan yang nyaman dan bahagia muncul dan dirasakan oleh ibu hamil setelah melakukan pijat secara rutin selama masa kehamilan berlangsung. Hal ini didukung oleh Aprilia (2017:81) menjelaskan hormon endorphine yang dihasilkan dari pijatan dapat menghilangkan rasa sakit dan menimbulkan perasaan bahagia pada ibu hamil. Kuswenda, Siswanti, dkk (2016:07) juga menyatakan pijatan yang diberikan dapat merangsang hormon endorphine sehingga dapat merelaksasikan pikiran dan mengurangi kecemasan yang menimbulkan perasaan bahagia yang dirasakan oleh ibu hamil.

Lebih lanjut Becker (2007:114) menyatakan pijat yang diberikan pada ibu hamil dapat meningkatkan ketenangan sehingga meningkatkan kepercayaan diri dan menimbulkan perasaan bahagia selama masa kehamilan. Lebih lanjut Wijayanti (2009:225) menjelaskan pemijatan yang diberikan pada ibu hamil dapat membantu tubuh untuk merelaksasi sehingga dapat melegakan pernafasan serta mengurangi kegelisahan dan 
kecemasan yang terjadi pada ibu hamil sehingga membuat ibu hamil menjadi lebih tenang dan bahagia.

\section{Simpulan dan Saran Simpulan}

Berdasarkan hasil pembahasan dapat disimpulkan sebagai berikut:

1. Pijat ibu hamil dapat mengurangi spasme otot karena pijat dapat mengurangi ketegangan dari saraf dan otot, melancarkan sirkulasi darah ke seluruh tubuh, dan meningkatkan daya tahan tubuh ibu hamil.

2. Tata cara yang dilakukan praktisi dalam pengambilan pijat ibu hamil untuk mengurangi spasme otot yaitu:

a) Mempersiapkan alat (bantal, guling, handuk dan selimut) dan bahan (minyak dan krim) yang digunakan praktisi dalam pemijatan.

b) Tahapan pemijatan diawali dengan persiapan pasien dan wawancara untuk memastikan permasalahan ibu hamil. Membersihkan telapak kaki dan melakukan pelemasan.

c) Pengambilan pasien diawali dengan pemijatan lembut dilakukan pada daerah kaki, tangan, dan punggung menggunakan tiga teknik yaitu mengusap (effleurage), memutar (friksi) dan meremas (petrisage) sedangkan pada perut dengan gerakan mengusap (effleurage) dan kepala menggunakan gerakan mengusap (effleurage) dan memutar (friksi). Ketiga gerakan tersebut diberikan dengan gerakan lembut.

3. Implikasi yang ditimbulkan dari pijat ibu hamil yaitu mengurangi rasa nyeri pada punggung ibu hamil, meningkatkan kualitas tidur pada akhir kehamilan dan menimbulkan perasaan bahagia pada ibu hamil.

\subsection{Saran}

Berdasarkan pembahasan dan simpulan dapat disarankan beberapa hal sebagai berikut:

1. Dengan adanya penelitian ini diharapkan dapat memberikan manfaat dan wawasan tentang pijat ibu hamil, sehingga ibu hamil dapat menjaga kesehatan selama masa kehamilan dengan melakukukan pijat secara teratur pada masa akhir kehamilan.

2. Diharapkan adanya penelitian lebih lanjut dan mendalam tentang terapi pijat untuk ibu hamil.
3. Diharapkan dengan adanya penelitian ini, ada standar operasional prosedur mengenai pijat ibu hamil.

\section{Ucapan TerimaKasih}

Ucapan terima kasih ditujukan kepada institusi penyandang dana penelitian, bukan kepada dosen pembimbing.

\section{DaftarPustaka}

Aprilia, Yesie. 2017. Bebastakut Hamil dan Melahirkan. Jakarta : PT Gramedia Pustaka Utama.

Beker, Jordy. 2007. Terapi Pijat Memijat Diri Sendiri Guna Memperoleh Kesehatan Fisik dan Psikis. Jakarta: Prestasi Pustaka.

Dash dan Ramaswamy. 2006. Ayurveda Ilmu Pengobatan Tradisional India. Surabaya: Paramita.

Dharma, Surya. 2008. Pengolahan dan Analisis Data Penelitian. Direktorat Tenaga Kependidikan, Direktorat Jenderal Peningkatan MUTU pendidik dan Tenaga Kependidikan, Departemen Pendidikan Nasional.

Diana, S. 2017. Pengaruh Pijat Bumil Terhadap Kualitas Tidur Pada Ibu Hamil Trimester III Di BPM Bidan A Desa Karang Nongko Kec.Soongko Kabupaten Mojokerto. Sekolah Tinggi Ilmu Kesehatan Majapahit. Hal:154-156

Fauziah.S. dan Sutejo. 2012. Keperawatan Maternitas Kehamilan vol 1. Jakarta: Kencana Prenada Media. .

Govinda, S. V. 1996. Massage for Healt and Healing. New Delhi: Abhinav Publications.

Hidayati dan Mangoenprasodjo. 2005. Terapi Alternatif \& Gaya Hidup Sehat. Yogyakarta: Pradipta Publishing.

Joseoh,C.R., Cherian,A. CT, Joseph. 2012. Role of Abhyanga (oil massage) to lead a healthy life. Kerala, India : Ayurpharm Int J Ayur Alli Sci., Vol 1 No 7. Hal 163-167.

Kartikasari, R I. dan Nuryanti, A. 2016. Pengaruh Endorphin Massage Terhadap Penurunan Intensitas Nyeri Punggung Ibu Ham 70 Lamongan: STIKES Muhammadiy Lamongan. Rakernasaipkema 2016. Hal:297-304

Kaushal,S. Lohith,BA. dan Ashvini.M.K. 2017. Abhyanga: Different Contemporary Massage Technique and its Importance in 
Ayurveda. Karnataka, India: Journal of ayurweda and integrated medical sciences. Hal 245-251

Kavanagh, Wendy. 2008. Sehat dengan Pijat. Jogjakara: Luna Publisher

Kuswenda.H.R.D. Siswati, Gita. Dkk. 2016. Pedoman Pijat Tradisional Indonesia. Jakarta: Kementrian Kesehatan RI.

Nala, Ngurah. 2001. Ayurveda Ilmu Kedokteran Hindu 1. Denpasar: Upada Sastra.

Ramesh. Gita, 2006. Ayurwedic Herbal Massage. India. Kailash-II

Wijayanti, Daru. 2009. Sehat Dengan Pengobatan Alami. Yogyakarta: Venus 